\title{
RAMAN VIBRATIONAL STUDY OF PIGMENTS WITH PATRIMONIAL INTEREST FOR THE CHILEAN CULTURAL HERITAGE
}

\author{
T. AGUAYO', E. CLAVIJO', A. VILLAGRÁN ${ }^{2}, F$. ESPINOSA', F. E. SAGÜÉE $S^{2}$ AND \\ M. CAMPOS-VALLETTE ${ }^{1 *}$
}

${ }^{1}$ Universidad de Chile, Facultad de Ciencias, Casilla 653 Santiago, Chile

${ }^{2}$ Centro Nacional de Conservación y Restauración (CNCR), DIBAM, Santiago, Chile.

(Received: November 26, 2009 - Accepted: August 18, 2010)

\begin{abstract}
Seven pigments of patrimonial interest for the Chilean artwork were analyzed by means of Raman spectroscopy by using the $632.8 \mathrm{~nm}$ excitation laser line. Samples were supplied by the National Center of Conservation and Restoration of Chile (CNCR) in a cooperative effort to determine the exact molecular composition of each pigment. In this contribution we propose to settle the use of the Raman spectroscopy as a method to contribute to the conservation and/or restoration procedures, and thus to the authentication of the works of art. Data collected were compared with published works confirming the reliability of Raman spectroscopy in this field of research.
\end{abstract}

\section{INTRODUCTION}

Molecular recognition of pigments, and other materials, in conservation arts is very important. The adequate identification of chemical species in a work of art ensures that the materials characterized will provide valuable information. The vibrational spectroscopy, a structural tool, with the infrared, Raman and surface enhanced Raman scattering (SERS) techniques along with new Raman performed instrumentation have been extensively used in conservation science ${ }^{1-3}$.

The benefits of Raman spectroscopy are notorious, since samples needed are minimal in case that data could not be collected in-situ ${ }^{4,5}$ or right in the object of study. The data collecting spectral process is also non-destructive ${ }^{6}$ which is huge advantage among other methods for molecular recognition. The obtained information could avoid some unwanted visual effects due to undesired chemical reactions in the restoration process. Also can lead to choose the best method to remove a pollutant and/or consolidate the piece by knowing the degradation products of pigments ${ }^{7-9}$. Another usage of this technique is to determine authenticity and dating of objects by knowing the artist's palette and checking that the pigments found on it correspond to the date of first manufacture or usage. This aims to achieve a better understanding of the object studied in terms of its comprehension, conservation and also in the unique moment for the life of an object as the restoration.

The present work should contribute to give solid information on the different aspects of the work of professionals involved in the identification, restorations and preservation of cultural heritage art pieces using the vibrational knowledge and expertise. At present the spectral information here obtained is inserted in the study of the identification of pigments of a wall painting (unknown author) recently unveiled in the San Francisco church, in Santiago, Chile, and in the diagnosis of the wall painting Historia de Concepción, by Gregorio de la Fuente, in the ancient Concepción train station.

\section{EXPERIMENTAL}

2.1 Samples

Samples were provided by the CNCR and consisted in seven pigments from a Kremer standard set catalogued as displayed in Table 1. Samples are mostly common pigments used in contemporary art, excepting the magnetite.
Table 1. Pigment samples catalogued as received from CNCR.

\begin{tabular}{|c|c|c|}
\hline Catalogue Number & Name & Color \\
\hline PIG008 & Zinc White (lead-free) & White \\
\hline PIG028 & Cadmium Yellow \#9,5 & Yellow \\
\hline PIG047 & Alizarin Crimson, dark & Red \\
\hline PIG072 & Chrome Green, dark & Green \\
\hline PIG085 & Ultramarine Blue, light & Blue \\
\hline PIG138 & Naples Yellow, light & Yellow \\
\hline PIG169 & Iron Oxide Black & Black \\
\hline
\end{tabular}

2.2 Raman measurements

All spectra were collected using a Renishaw Raman System 1000 equipped with a He-Ne laser (excitation wavelength $632.8 \mathrm{~nm}$ ), an $\mathrm{Ar}^{+}$laser (excitation wavelength $514.5 \mathrm{~nm}$ ) and a Leica microscope. The site for incident radiation was focused through a 50x objective. Spectra were recorded from 200 to 1800 $\mathrm{cm}^{-1}$ and the samples were exposed between 10 and 30 seconds taking from 1 to 5 accumulations. Radiation of $632.8 \mathrm{~nm}$ from the He-Ne laser was used as excitation source and the power was set from $1 \%$ to $100 \%$ as needed to obtain the best spectra.

\section{RESULTS AND DISCUSSION}

The first approach to the pigments composition was proposed on the basis of the names already published ${ }^{10}$. Results are summarized in Table 2 indicating the identification according to the Color Index (CI) name, the former catalogue number and the generic name (or the compound name in the case that there is not generic name); also the formula and the main Raman bands are displayed. The spectra are shown as obtained and are illustrated along with the discussion.

\subsection{PIG008 Zinc White}

Zinc White corresponds to Zinc (II) oxide, with wurtzite like crystal structure (w-ZnO), which was first produced as a white pigment in the 1780's. Because of its poor attributes when used in oil was not popular until $1834{ }^{10}$ when it was sold under the name of Chinese White.

The $\mathrm{w}-\mathrm{ZnO}$ belongs to the $\mathrm{C}_{6 \mathrm{y}}$ group of symmetry, and the symmetry species that show Raman activity (Fig. 1) are ${ }^{11}$ : A transverse optical phonon (A-TO) at $380 \mathrm{~cm}^{-1} ; \mathrm{E}_{1}-\mathrm{TO}$ at $409 \mathrm{~cm}^{-1} ; \mathrm{E}_{1}-\mathrm{LO}$ at $582 \mathrm{~cm}^{-1}$ and $\mathrm{E}_{2}$ high $\left(\mathrm{E}_{2} \mathrm{~h}\right)$ at $437 \mathrm{~cm}^{-1}$. These bands are consistent with previous works ${ }^{12,13}$ for the $\mathrm{w}-\mathrm{ZnO}$. The bands at 330,541 and $665 \mathrm{~cm}^{-1}$ are ascribed to possible multi-phonon scattering processes ${ }^{12,14}$, and the bands at 1076 and $1150 \mathrm{~cm}^{-1}$ were assigned to multi-photon effects by Bouchard and Smith ${ }^{15}$. No contaminant products were found. 
Table 2. Results analysis.

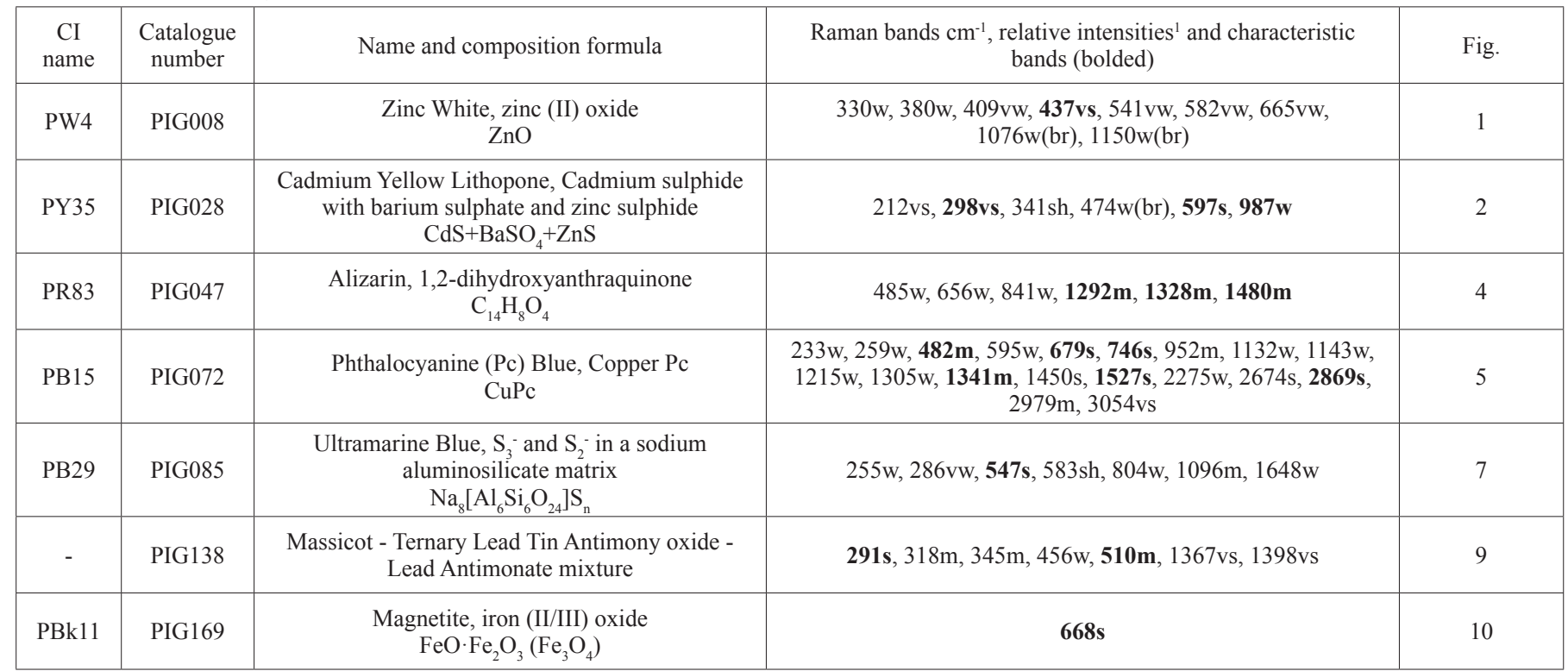

${ }^{1}$ Relative intensity: v, very; w, weak; m, medium; s, strong; sh, shoulder; br, broad

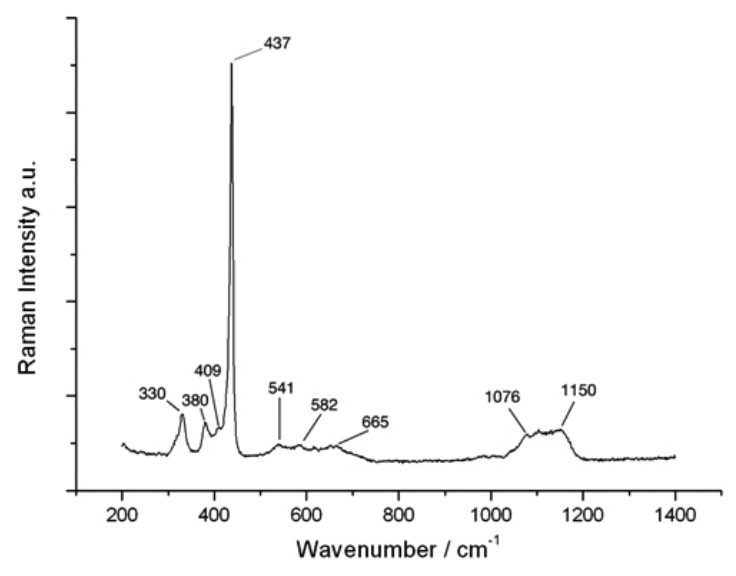

Figure 1. Raman spectrum of PIG008. 1 scan, 100\% laser power.

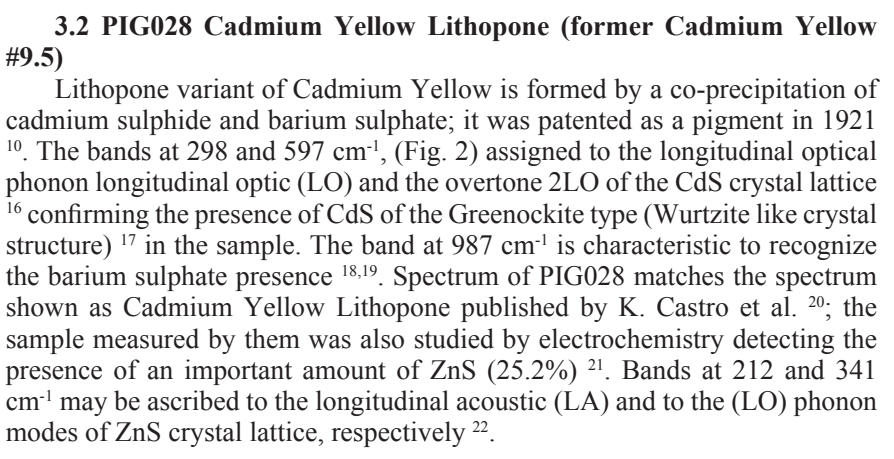

3.2 PIG028 Cadmium Yellow Lithopone (former Cadmium Yellow

Lithopone variant of Cadmium Yellow is formed by a co-precipitation of culpum sulphide and barium sulphate; it was patented as a pigment in 192 ${ }^{10}$. The bands at 298 and $597 \mathrm{~cm}^{-1}$, (Fig. 2) assigned to the longitudinal optical phonon longitudinal optic (LO) and the overtone $2 \mathrm{LO}$ of the CdS crystal lattice ${ }^{16}$ confirming the presence of CdS of the Greenockite type (Wurtzite like crysta in the sample. The band at $987 \mathrm{~cm}^{-1}$ is characteristic to recognize shown as Cadmium Yellow Lithopone published by K. Castro et al. 20. the sample measured by them was also studied by electrochemistry detecting the modes of $\mathrm{ZnS}$ crystal lattice, respectively ${ }^{22}$. 
$\left.\mathrm{cm}^{-1}\right)$; and $\mathrm{CO} / \mathrm{CC}$ stretching plus $\mathrm{CH}$ out-of plane bending $\left(1480 \mathrm{~cm}^{-1}\right)^{25}$. The baseline observed in the alizarin spectrum (Fig. 4) is due to natural fluorescence of the alizarin molecule; it might be attenuated using Surface Enhanced Raman Spectroscopy (SERS) ${ }^{25}$.

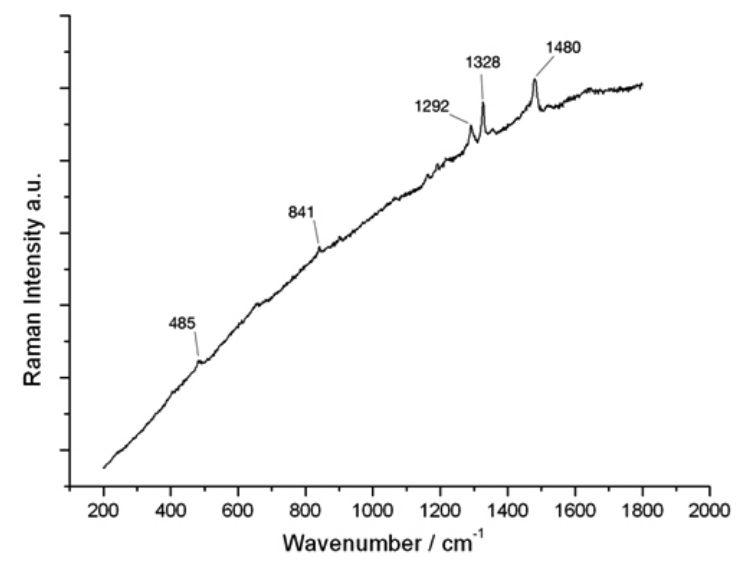

Figure 4. Raman spectrum of PIG047. 2 scans, 1\% laser power.

\subsection{PIG072 Chrome Green.}

The case of this pigment in the present investigation is the most representative example of the usefulness of Raman spectroscopy in the field of pigment recognition. The sample provided was tagged under the name of Chrome Green which should correspond to a chrome (III) oxide ${ }^{10}$, with expected bands around 350, 552 and $614 \mathrm{~cm}^{-1} 19,20$, or to an intimate mixture of Chrome Yellow and Prussian Blue, with bands expected at 279, 360, 532, 845,2092 and $2153 \mathrm{~cm}^{-1}{ }^{16}$, both with a strong inorganic character. However, these characteristic bands were not observed; a presumably organic spectrum, see figure 5 , was obtained instead.

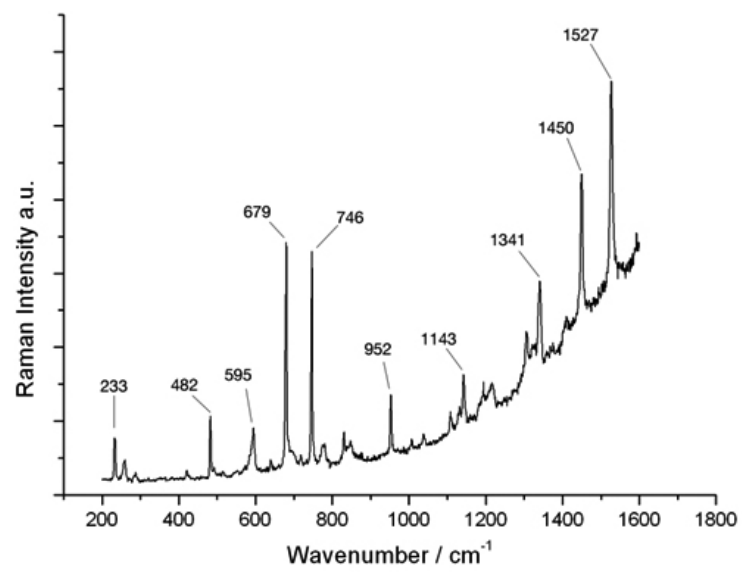

Figure 5. Raman spectrum of PIG072. 1 account, 1\% laser power.

The pigment sample corresponds to a copper phthalocyanine $(\mathrm{CuPc})^{23}$ (Fig. 6). Phthalocyanines are macrocycles formed by four isoindole units that have the ability to coordinate different metal atoms ${ }^{26}$. The most intense bands shown on Fig. 6 at 482, 595, 679, 746, 952, 1143, 1341, 1450 and $1527 \mathrm{~cm}^{-1}$ are assigned to $A_{2 g}, B_{2 g}, A_{1 g}, B_{1 g}, B_{2 g}, B_{2 g}, A_{1 g}, B_{2 g}$ and $A_{1 g}$ symmetry species, respectively ${ }^{27,28}$. Bovill et al carried out a complete band assignment ${ }^{28}$.

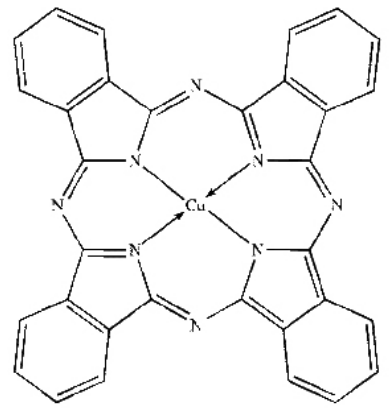

Figure 6. Copper phthalocyanine structure.

Phthalocyanines started to be used as pigment right after its discovery back in $1929^{10}$. Thus, the Chrome Green pigment in the original sample is not chrome (III) oxide but copper phthalocyanine.

\subsection{PIG085 Ultramarine Blue}

According to published works ${ }^{29,30}$ the Raman spectrum (Fig. 7) of the pigment corresponds rather to Ultramarine Blue, the synthetic equivalent of Lazurite. Lazurite is the main component in the precious stone called Lapis Lazuli. The use of Ultramarine Blue as a replacement of Lapis Lazuli began in 1787 in Italy ${ }^{10}$. The other components of Lapis Lazuli are calcite and pyrite, and since none of the main bands of those minerals ${ }^{30}$ appears on the spectra taken for this sample, the synthetic origin is inferred.

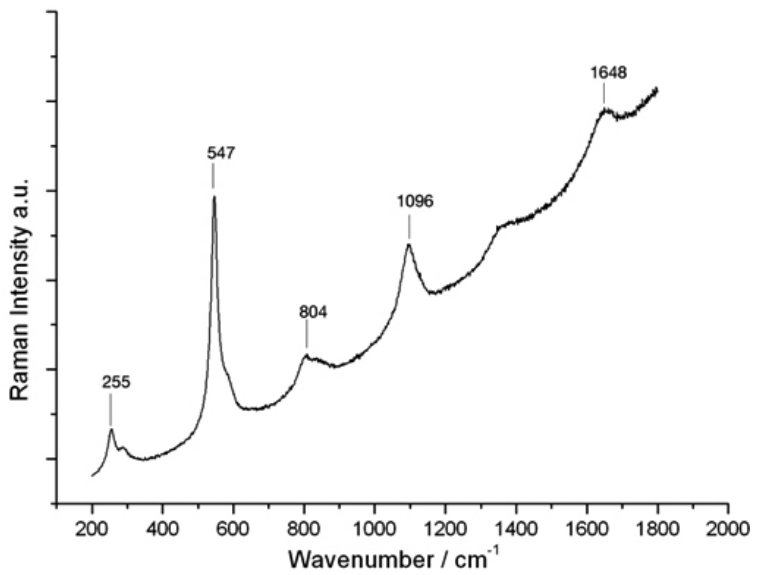

Figure 7. Raman spectrum of PIG085. 1 account, $10 \%$ laser power.

Synthetic Ultramarine Blue corresponds to a sodium aluminosilicate matrix with sulphur ions $\left(\mathrm{S}_{3}^{-}, \mathrm{S}_{2}^{-}\right)$in it; the generic formula for this kind of material is shown in Table 2 .

On the microscope two types of crystals are distinguished, blue and white ones. The comparison between the spectra (Fig. 8) of both types suggests that they are the same compound.

The observed band at 547,255 and $583 \mathrm{~cm}^{-1}$ correspond to the symmetric stretching mode $v_{1}$, the bending mode $v_{2}$ and to the anti-symmetric stretching mode $v_{3}$ of the $\mathrm{C}_{2 \mathrm{v}} \mathrm{S}_{3}$ ion (blue), respectively ${ }^{31}$; the other bands correspond to combination bands of the $v_{1}, v_{2}$ and $v_{3}$, modes (e.g. $547+255=802 \mathrm{~cm}^{-1}$ ) 31,32 The $\mathrm{S}_{2}$ - ion (yellow) is characterized by a band (shoulder) observed ca. 590 $\mathrm{cm}^{-1} 32$; the $\mathrm{S}_{2}$ ion is responsible for the green hue of some of the Ultramarine pigments. 


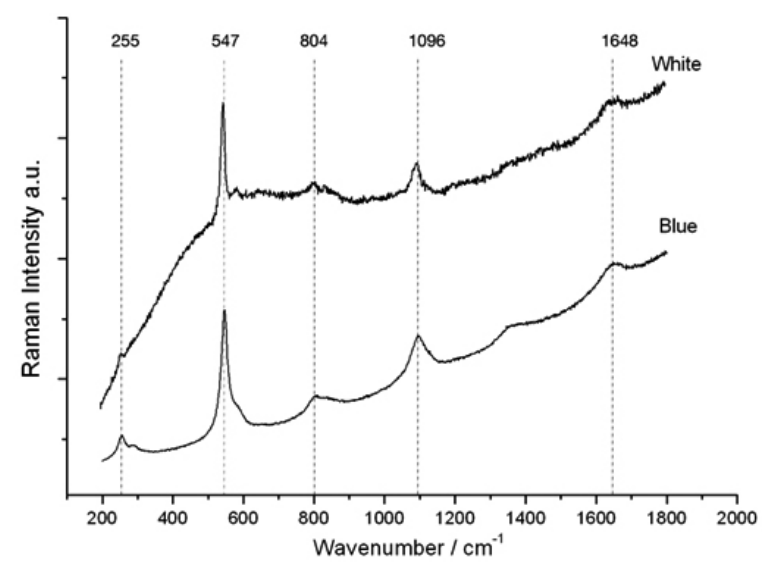

Figure 8. Comparison between the 2 types of crystals in the sample.

3.6 PIG138 Massicot - Ternary Lead Tin Antimony oxide - Lead Antimonate mixture (former Naples Yellow)

Lead based yellow pigments had been used since antiquity; they consist in lead oxides, lead-tin oxides (type I and II) and lead-antimony oxides (Naples Yellow being one of them), characterized by a strong band between 127 and $145 \mathrm{~cm}^{-1}$ (Fig. 9) attributed to $v \mathrm{~Pb}-\mathrm{O}{ }^{33}$. In particular, lead antimony oxides are synthetic analogues to the bindehimite that presents a pyrochlore crystal structure ${ }^{10}$. This type of crystal structure shows the ideal formula $\mathrm{A}_{2} \mathrm{~B}_{2} \mathrm{O}_{7}$ (Naples yellow most accepted formulation is $\mathrm{Pb}_{2} \mathrm{Sb}_{2} \mathrm{O}_{7}$ ) where $\mathrm{A}$ and $\mathrm{B}$ can be replaced by cations such as $\mathrm{Pb}(\mathrm{II}), \mathrm{Sb}(\mathrm{II}), \mathrm{Sn}(\mathrm{II}), \mathrm{Zn}(\mathrm{II}), \mathrm{Bi}(\mathrm{II})$, getting octahedral coordination when they are in B position. In fact, the band at 510 $\mathrm{cm}^{-1}$ is assigned ${ }^{34}$ to the symmetrical stretching of the octahedral formed by the $\mathrm{Sb}-\mathrm{O}$ bonds when $\mathrm{Sb}$ occupies the B position; this situation can occur in more than one case in the context of yellow lead based pigments. Besides Naples Yellow, mentioned above, the band at $510 \mathrm{~cm}^{-1}$ can be observed in a Ternary oxide of $\mathrm{Pb}-\mathrm{Sn}-\mathrm{Sb}{ }^{35}$. The other important bands could suggest the presence of Massicot, as it is present in the synthesis of both Naples Yellow and the Ternary Oxide ${ }^{35,36}$, and a Lead-Tin Oxide $\left(\mathrm{Pb}_{2} \mathrm{SnO}_{4}\right)^{37}$. As no information was obtained below $200 \mathrm{~cm}^{-1}$, the species mentioned above are just proposed ${ }^{16}$.

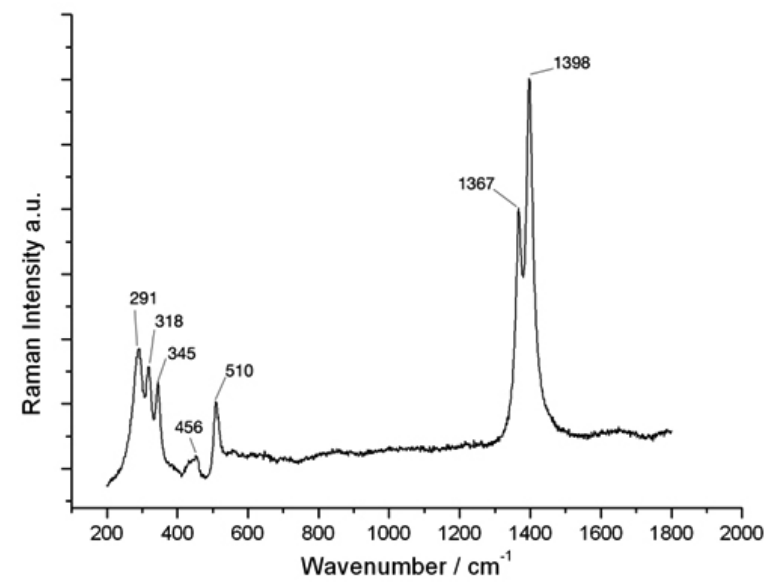

Figure 9. Raman spectrum of PIG138. 1 scan, 10\% laser power.

3.7 PIG169 Magnetite (former Iron Oxide Black)

The $A_{1 g}$ band at $668 \mathrm{~cm}^{-1}$ (Fig. 10) identifies Magnetite ${ }^{15,37}$, a magnetic mineral that consists in an Iron (II/III) Oxide observed mainly in igneous and metamorphic rocks ${ }^{10}$. The Raman spectrum of this sample (Fig. 10) was difficult to obtain because its black color. The observed slight asymmetry towards the high frequencies of the band centered at $668 \mathrm{~cm}^{-1}$ suggests the coexistence of the iron (II) and (III) oxidation states as it is in the original sample. The other bands at 538 and $306 \mathrm{~cm}^{-1}$ were also observed by Shebanova and Lazor ${ }^{38}$; these authors compared their results with other Raman studies indicating that discrepancies with the earlier data arise from photo-oxidation processes occurring during the Raman experiments. Under the spectral acquisition conditions here used no spectral modifications were observed by laser effect.

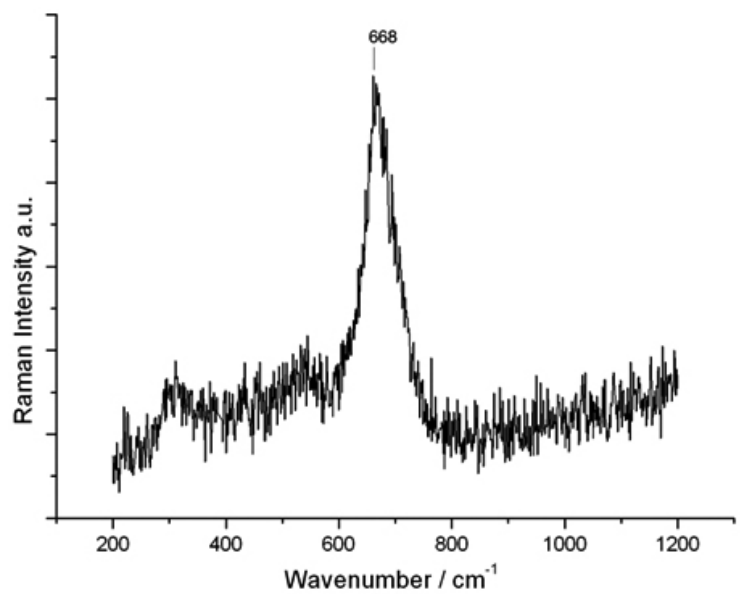

Figure 10. Raman spectrum of PIG169. 5 scans, 1\% laser power.

\section{CONCLUSION}

Six of the seven pigments analyzed were successfully recognized and/or confirmed using Raman spectroscopy. This technique results to be useful in the fields of material characterization for cultural matters, namely conservation and restoration of artwork. Data bases available now days gathering Raman characterization for common materials used in art, whether they are published on journals or on-line, are widely accessible and reliable, increasing the importance of Raman spectroscopy as a complementary tool for comprehension, conservation and restoration of the works of art. Finally, recent published results concerning anthocyanin ${ }^{39}$, a pigment extracted from copihue, will be extremely useful in the characterization of Chilean art pieces painted using that pigment.

\section{REFERENCES}

1. Z. Jurasekova, J.V. García Ramos, C. Domingo and S. Sánchez Cortés, J. Raman Spectrosc., 37 (2006) 1239.

2. R.J.H. Clark, Appl. Phys. A 89, 833-840 (2007)

3. D. Bersani, P.P. Lottici, F. Vignali and G. Zanichelli, J. Raman Spectrosc., 37 (2006)1012; L. Burgio, R.J.H. Clark, V. Muralha, and T. Stanley, T., J. Raman Spectrosc., 39 (2008) 1482.

4. P. Vandenabeele, K. Castro, M. Hargreaves, L. Moens, J.M. Madariaga, H.G.M. Edwards, Anal. Chim. Acta 588, 108, (2007)

5. R.J.H. Clark, C. R. Chimie 5, 7, (2002)

6. S. Ruiz-Moreno, R. Pérez-Pueyo, A. Gabaldón, M. Soneira, C. Sandalinas, J. Cultural Heritage 4, 309, (2003)

7. R.L. Frost, Spectrochim. Acta, Part A 59, 1195, (2003)

8. L. Burgio, R.J.H. Clark, S. Firth, Analyst 126, 222, (2001)

9. W. Martens, R.L. Frost, J.T. Kloprogge, P.A. Williams, J. Raman Spectrosc. 34, 145, (2003)

10. N. Eastaugh, V. Walsh, T. Chaplin, R. Siddall, Pigment Compendium: A Dictionary and Optical Microscopy of Historic Pigments, Elsevier Butterworth-Heinemann, 2004

11. H. Morkoc, Ü. Özgür, Zinc Oxide - Fundamentals, Materials and Device Technology, Wiley-VCH, Berlin, 2009; p 37-46.

12. T. C. Damen, S. P. S. Porto, B. Tell, Phys. Rev. 142, 570, (1966)

13. Y. Wu, Z. Xi, G. Zhang, J. Zhang, D. Guo, Crystal Growth \& Design 8, 2646, (2008)

14. J. M. Calleja, M. Cardona, Phys. Rev. B, 16, 3753, (1977)

15. M. Bouchard, D.C. Smith, Spectrochim. Acta, Part A 59, 2247, (2003)

16. A.M. Correia, R.J.H. Clark, M.I.M. Ribeiro, J. Raman Spectrosc. 38, $1390,(2007)$

17. Site: http://rruff.info/

18. L. Burgio, R.J.H. Clark, Spectrochim. Acta, Part A 57, 1491, (2001) 
19. I.M. Bell, R.J.H. Clark, P.J. Gibbs, Spectrochim. Acta, Part A 53, 2159, (1997)

20. K. Castro, M. Pérez-Alonso, M.D. Rodríguez-Laso, L.A. Fernández, J.M. Madariaga, Anal. and Bioanal. Chem. 382, 248 (2005)

21. G. Cepriá, E. García-Gareta, J. Pérez-Arantegui, Electroanalysis 17, 1078 (2005)

22. Q. Xiong, J. Wang, O. Reese, L. Voon, P. Eklund, Nano Letters 4, 1991, (2004)

23. N.C. Scherrer, Z. Stefan, D. Francoise, F. Annette, K. Renatetal, Spectrochim. Acta A, 73, 505, (2009)

24. I.T. Shadi, B. Z. Chowdhry, M. J. Snowden, R. Withnall, J. Raman Spectrosc. 35, 800, (2004)

25. M. Cañamares, J. Garcia-Ramos, C. Domingo, S. Sanchez-Cortes, J. Raman Spectrosc. 35, 921, (2004)

26. D. R. Tackley, G. Dent, W. E. Smith, Phys. Chem. Chem. Phys. 3, 1419, (2001)

27. J. Dowdy, J. J. Hoagland, K. W. Hipps, J. Phys. Chem. 95, 3155, (1991)

28. A. J. Bovill, A. A. McConnell, J. A. Nimmo, W. E. Smith, J. Phys. Chem. 90, 569, (1986)
29. L. Burgio, R. J. H. Clark, L. Sheldon, G. D. Smith, Anal. Chem. 77, 1261, (2005)

30. M.L. Franquelo, A. Duran, L.K. Herrera, M.C. Jimenez de Haro, J.L. Perez-Rodriguez, J. of Mol. Struct. 924-926, 404, (2009)

31. B. Ledé, A. Demortier, N. Gobeltz-Hautecœur, J.-P. Lelieur, E. Picquenard, C. Duhayon, J. Raman Spectrosc. 38, 1461, (2007)

32. Ph. Colomban, J. Raman Spectrosc. 34, 420, (2003)

33. L. D. Kock, D. De Waal, Spectrochim. Acta, Part A 71, 1348, (2008)

34. F. Rosi, V. Manuali, C. Miliani, B. Brunetti, A. Sgamellotti, T. Grygar, D. Hradil, J. Raman Spectrosc. 40, 107, (2009)

35. C. Sandalinas, S. Ruiz-Moreno, A. López-Gil, J. Miralles, J. Raman Spectrosc. 37, 1146, (2006)

36. K. Sakellariou, C. Miliani, A. Morresi, M. Ombelli, J. Raman Spectrosc. 35, 61, (2004)

37. P. Baraldi, A. Tinti, E.L. Kendix, G. Moscardi, R. Mazzeo, P. Baraldi, S. Prati, E. Joseph, S. Capelli, J. Raman Spectrosc. 39, 1104, (2008)

38. O.N. Shebanova, P. Lazor, J. Solid State Chem. 174, 424, (2003)

39. C. Vergara, D. von Baer, I. Hermosín, A. Ruiz, M.A. Hitschfeld, N. Castillo and C. Mardones. J. Chil. Chem. Soc, 54, nº 2 (2009) 